\title{
Longitudinal changes in the neutral oligosaccharide content in the milk from mothers of pre-term and full-term infants during lactation: A single-centre observational study.
}

\author{
Sean Austin ${ }^{1}$, Carlos Antonio De Castro ${ }^{2}$, Norbert Sprenger ${ }^{1}$, Clara Garcia-Rodenas ${ }^{1}$, Michael Affolter ${ }^{1}$, Chiara \\ Nembrini ${ }^{1}$, Lydie Beauport ${ }^{3}$, Jean-Francois Tolsa ${ }^{3}$, Céline Fischer Fumeaux ${ }^{3}$
}

${ }^{1}$ Nestlé Research, Lausanne, Switzerland. ${ }^{2}$ Nestlé Research, Singapore. ${ }^{3}$ University Hospital (CHUV), Neonatology Department, Lausanne, Switzerland

\section{Background}

Human milk feeding reduces the risk of morbidity and improves (neuro)development in preterm infants $[1,2]$. Some of the benefits of human milk feeding may be derived from the human milk oligosaccharides (HMOs), which are a major constituent of human milk. . Although there are a lot of data describing the HMO content of term milk, the data are rather variable, due to differences in milk collection procedures, analytical procedures and biological variation. The HMO content of preterm milk has been much less studied, and the studies which do exist have the same limitations as for the studies on term milk.

\section{Objective}

Compare the content of the major neutral HMOs between pre-term and term milk along lactation.

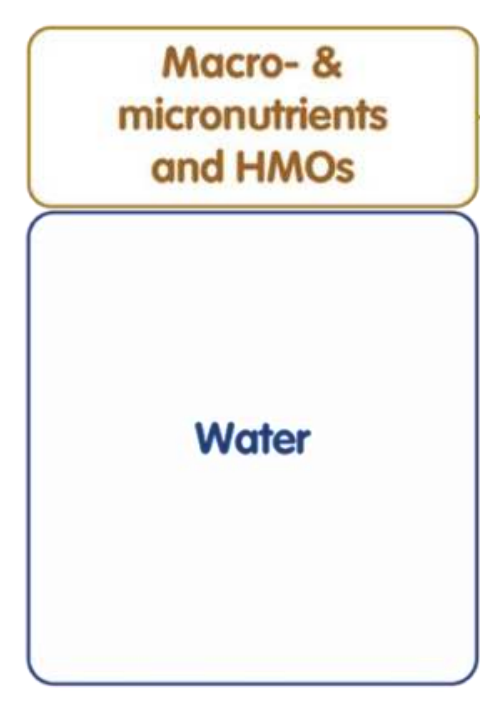

Breast milk

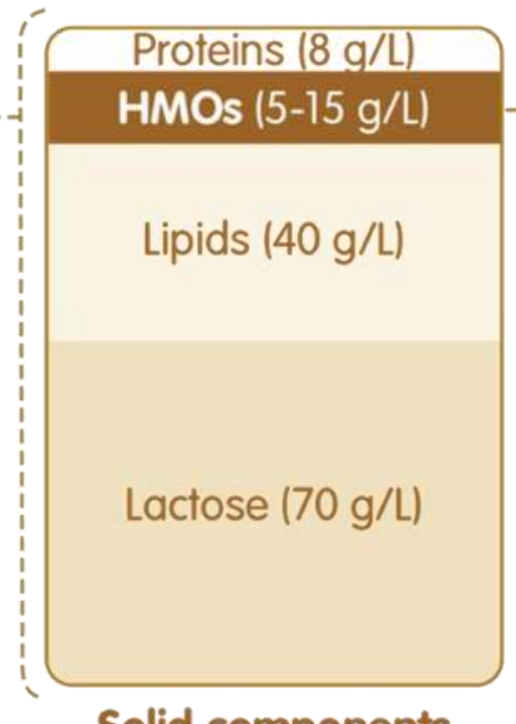

Solid components

\section{Design}

Human milk was collected from mothers of 27 pre-term infants (28-32 weeks of gestation) and 34 full-term infants (>37 weeks of gestation) living in Switzerland. Milk was collected once per week for 8 weeks (term group) or 12 weeks (pre-term group) post-partum, and the concentrations of 16 neutral HMO were measured by liquid chromatography as described previously [3]. The HMO content of Preterm and term milk were compared using mixed linear models at equivalent (1) post-partum age and (2) post-menstrual age.

\section{Results}
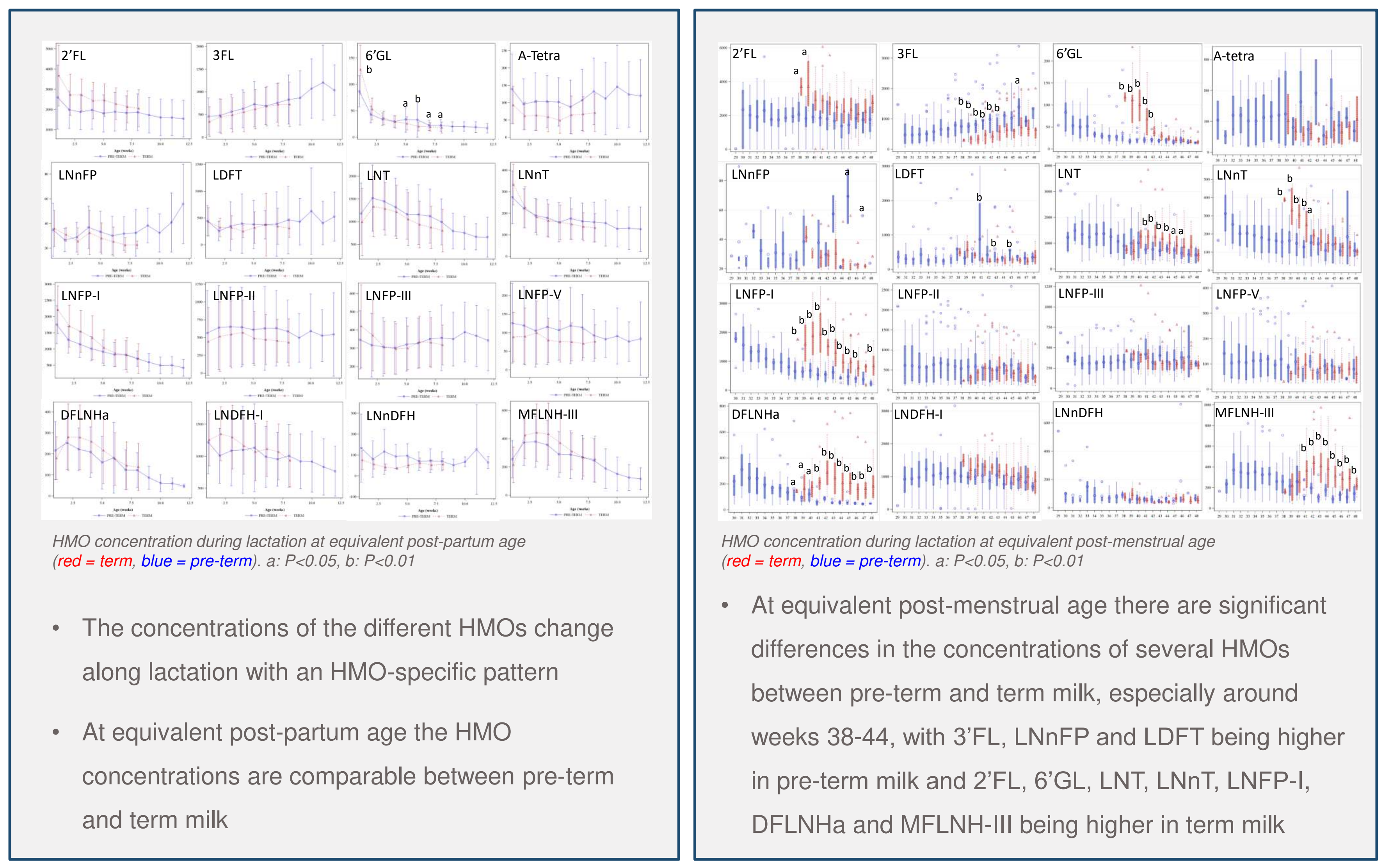

The study was sponsored by Nestlé Research, Lausanne (Nestec Ltd) and registered at www.clinicaltrial.gov under the number NCT02052245

\section{Acknowledgements}

We thank all the study participants and the study teams. Sincere thanks to Nassima Grari, the study lactation nurse who took care of all the mothers for the duration of the study.

\section{References}

(1) Corpeleijn,W. E., Kouwenhoven,S.M., et.al. (2012) Neonatology 4: 276-281. http://dx.doi.org/10.1159/000341335

(2) Lechner,B.E. \& Vohr,B.R. (2017) Clinical Perinatology 44: 69-83. http://dx.doi.org/10.1016/j.clp.2016.11.004

(3) Austin,S. \& Benet,T. (2018) Analytica Chimica Acta 1010: 86-96. http://dx.doi.org/10.1016/j.aca.2017.12.036 